\title{
Understanding stress and coping mechanisms in Indian student nurses
}

\author{
Aniket Shukla, Gurvinder Kalra, Abhijit Pakhare
}

\section{Introduction}

Nursing education and profession remain challenging and stressful with stress arising secondary to role conflict, role demand and role transition. Persistent stress from various sources could affect coping mechanisms which may lead to psychological distress and disorders. Unfortunately there are no mechanisms to address these issues. Hence it is important to identify the sources of stress and existing patterns of coping behavior in student nurses to help plan interventions. Aims

The aim was to assess the level and source of stress, coping mechanisms and influencing factors in student nurses.

\section{Method}

This was a cross-sectional study. Fifty nine student nurses from 2 nd and $3 r d$ year, pursuing their general nursing and midwifery course were assessed using the Student Nurse Stress Index (SNSI), Moo's Coping Response Inventory and a socio-demographic questionnaire.

Results

Mean score of SNSI was 59.3 indicating significant stress. Academic load and pattern of interpersonal interactions in college and home environments (interface worries) were the major source of perceived stress. Students perceived the restrictive environment, lack of quality free time, and inconsistent faculty responses to their concerns as likely reasons of their distress. Use of "approach mechanisms" was significantly higher than "avoidance coping" but both were equally used while handling stress due to academic load and interface worries. Factors like family size, responsibility and opting for a nursing career by choice affected stress and coping patterns. Conclusion

Though there has been adequate clinical skills training in the nursing curriculum, little attention is paid to make the working environment less stressful and more conducive to healthy interactions. A positive trend was evident in use of "approach" over "avoidance" coping strategies. Time and stress management and use of effective coping skills to handle academic and interpersonal stress and introducing andragogical teaching methods should be incorporated early in the nursing curriculum.

SL J Psychiatry 2012; 4 (2):29-33

\section{Introduction}

Nursing is a demanding profession which requires the ability to withstand stressful situations like death and emergencies (1). It also needs good academic knowledge and skills, as well as dedication to the profession. The job demands good time management to accomplish multiple tasks in a short span of time. It also requires the ability to be on the feet while on duty, withstand sleepless nights, cope with emergencies, and handle difficult situations by staying calm and providing support and care to patients and their families. These facets have to be acquired during the training period making this period rather demanding and stressful.

Stress during nursing training is also influenced by role transition, role demand and role ambiguity. The ability to cope with these stressors is influenced by various personal and environmental factors. While studies indicate increased autonomy and independence during the transition period, they experience significant initial difficulty in adjusting to the new environment especially those who migrate for studies or work. They also need to function in a competitive academic environment which demands physical fitness, and mental stability (role demand) (2).
These students often leave home for the first time when going to nursing college and may experience ambivalent feelings because of the need for family support and need for independence at the same time (role conflict). The higher academic expectations in college compared to that in high school increase their stress further (3). Long hours of study and duties, multiple assignments, lack of free time and poor faculty response to student needs are other major contributors to stress (4). Similarly environmental differences, age, responsibility towards family, worries regarding work personal shortcomings are other contributors to stress $(5,6)$.

Stress due to various causes could lead to psychological distress and psychosomatic illness. Studies have shown that nursing students are vulnerable to sleep disorders, eating disorders, and other psychosomatic illnesses (79). Ability to handle stress is largely determined by the coping mechanisms used by the person. Studies have indicated that trainee nurses may become vulnerable to stress because of the use of less effective coping strategies such as avoidance when handling stress $(9,10)$.

There are only a few studies of student nurses or nursing professionals in India. There is little data on 
stress and coping styles in student nurses in India. Increasing referrals of student nurses for psychiatric consultation indicate that this population experience considerable stress. The aim of the current study was to assess the perceived level and source of stress, coping mechanisms and influencing factors in student nurses of 2 nd and 3rd year nursing school pursuing revised General Nursing and Midwifery Course in a Tertiary Care Medical Hospital and compared the difference in the coping patterns between the two groups.

\section{Methods}

This was a cross sectional. Sample was selected from 2nd and 3rd year students following the revised General Nursing and Midwifery Course in a tertiary care Medical Hospital. The study was conducted at the start of the term and hence 1st year students, who were recently admitted, were excluded because the initial period of stress while adjusting to the new environment may be a transient and a normal phenomenon which could bias study results. All 2nd and 3rd year students were approached to participate in the study. Written consent was obtained. Fifty nine students completed the study. They were assessed individually using following tools;

\section{Socio demographic questionnaire}

Age, family size, role in the family, career preferences and history of long-term illness or medication were recorded. Open ended questions assessed perceived sources of stress. Themes of subjective perception were identified through written narratives.

\section{Student Nurse Stress Index (SNSI)}

SNSI is a 22-item standardized scale for assessing stress levels due to academic load, clinical sources, interface worries, and personal problems (11). Stress due to clinical sources measure stress related to clinical work during the training period. Interface worries primarily include stress experienced by students in interactions with different people in the college and home environment. Response to these questions was measured on a five point Likert scale of 1 (not stressful at all) to 5 (extremely stressful). The reliability coefficient (Cronbach's alpha) was 0.768 which indicated good reliability.

\section{Moo's Coping Response Inventory - adult}

This is a 48-item scale used for measuring eight different types of coping responses to life circumstances; logical

\begin{tabular}{|l|l|l|}
\hline \multicolumn{2}{|c|}{ Table 1- Mean total and sub scale SNSI scores } \\
& Mean(SD) & $95 \% \mathrm{Cl}$ \\
\hline SNSI score & $59.3(10.82)$ & $56.52-62.16$ \\
Academic load & $23.9(3.97)$ & $22.91-24.98$ \\
Interface worries & $16.5(4.39)$ & $15.35-17.64$ \\
Clinical source & $9.8(2.59)$ & $8.98-10.58$ \\
Personal problems & $10.6(2.04)$ & $10.05-11.11$ \\
\hline
\end{tabular}

analysis (LA), positive reappraisal (PR), seeking guidance and support (SG), problem solving (PS), cognitive avoidance (CA), seeking alternative rewards (SR), acceptance or resignation (AR), and emotional discharge (ED) (12-14). The first four subscales measure "Approach Coping" and remaining four subscales measure "Avoidance Coping" strategies. Individuals with "Approach Coping" address the stressful situation directly, while those with "Avoidance Coping" solve the problem by avoiding it. This inventory has been employed in a number of populations, such as patients with alcohol problems, depressed patients and geriatric individuals. The CRI-Adult has been validated and used extensively by researchers $(15,16)$. The response to each item is measured on a four point likert scale from 1-4. The reliability co-efficient (Cronbach's alpha) of this instrument was 0.798 when used in our population.

Statistical analysis used Statistical Package for Social Sciences version 17 (SPSS-17) software. Descriptive statistics, proportions, means and 95\% confidence interval were used to describe scores of study instruments. Cronbach's alpha measured reliability of testing instruments. Repeated measure analysis of variance (ANOVA) was used for comparing scores of different domains of a scale e.g. sources of stress in SNSI, subgroups of approach coping and subgroups of avoidance coping mechanisms in Moo's Coping Response Inventory. Paired t-test was used to compare mean scores of "Approach" and "Avoidance" coping mechanisms.

\section{Results}

A total of 80 students were requested to participate in the study and 59 nursing students consented and completed the study. Response rate was $73.8 \%$. Thirty students were 2 nd year students and 29 were 3 rd year students. The response rate was $73.8 \%$. The reasons for non-participation were lack of time, absenteeism, and not consenting to participate. The participants were all females and were unmarried. The mean age was 19.27 years (SD 0.78). Of the sample $60.7 \%$ were from families of small size ( $<5$ members) while $39.7 \%$ were from large families.

Participants were asked to rate the perceived level of responsibility they felt towards their families. A large percentage of our study participants $(81.5 \%)$ perceived low to moderate responsibility towards their family while $10.2 \%$ perceived high level of responsibility.

\begin{tabular}{|c|c|c|c|c|}
\hline & $\begin{array}{l}\text { Academic } \\
\text { load }\end{array}$ & $\begin{array}{l}\text { Interface } \\
\text { worries }\end{array}$ & $\begin{array}{l}\text { Clinical } \\
\text { source }\end{array}$ & $\begin{array}{l}\text { Personal } \\
\text { problems }\end{array}$ \\
\hline $\begin{array}{l}\text { Academic } \\
\text { load }\end{array}$ & - & $\begin{array}{l}7.4 \\
(p<0.001)\end{array}$ & $\begin{array}{l}14.1 \\
(p<0.001)\end{array}$ & $\begin{array}{l}13.4 \\
(p<0.001)\end{array}$ \\
\hline $\begin{array}{l}\text { Interface } \\
\text { worries }\end{array}$ & $\begin{array}{l}-7.4 \\
(p<0.001)\end{array}$ & - & $\begin{array}{l}6.7 \\
(p<0.001)\end{array}$ & $\begin{array}{l}6.0 \\
(p<0.001)\end{array}$ \\
\hline $\begin{array}{l}\text { Clinical } \\
\text { source }\end{array}$ & $\begin{array}{l}-14.1 \\
(p<0.001)\end{array}$ & $\begin{array}{l}-6.7 \\
(p<0.001)\end{array}$ & - & $\begin{array}{l}-0.7 \\
(p<0.001)\end{array}$ \\
\hline $\begin{array}{l}\text { Personal } \\
\text { problems }\end{array}$ & $\begin{array}{l}-13.3 \\
(p<0.001)\end{array}$ & $\begin{array}{l}-5.9 \\
(p<0.001)\end{array}$ & $\begin{array}{l}0.7 \\
(p=0.516)\end{array}$ & - \\
\hline
\end{tabular}


Majority (81.4\%) of the students had opted for nursing as a career of choice. None of the participants had any chronic medical or surgical illness and none were on medications at the time of the study.

\section{Level and source of stress}

As shown in table 1, the mean score of perceived stress level according to SNSI in the study population was 59.3 (95\% CI 56.5-62.2) which indicated significant stress. There was no significant difference between 2 nd and 3rd year students in mean stress levels and in the different sources of stress $(\mathrm{t}$-value $=0.163, \mathrm{p}=0.871)$.

Repeated measure ANOVA test was used to compare sources of stress and it was observed that stress due to Academic load and Interface worries was significantly higher than other sources (Table 2). A sub-item analysis of the student nurse stress index scale revealed that $87 \%$ of the nursing students in our study perceived fear of failure in the examination and being unsure of what is expected from them in both academic activity and clinical work to be extremely stressful. A lack of timely positive feedback from the faculty despite good performance was also perceived stressful in the domain of "interface worries" in our study sample $(n=27 / 59)$. The other domains perceived as stressful by majority were "lack of free time for self" $(n=22 / 59)$.

Qualitative analysis of individual written narratives revealed the following as major themes regarding source of stress; inconsistency of faculty regarding student concerns and explanations, strict working and living environment due to restrictions imposed by faculty or instructors, difficulty in time management, fear of failure in academic assignments and demeaning experiences such as being looked down upon and given inferior status owing to their student nurse status (Table $3)$.

\section{Coping Mechanisms}

The mean score for "Approach Coping" was 65.11 (95\% CI 62.8-67.5), and for "Avoidance Coping" was 59.64 (95\% CI: 57.6 to 61.7). The use of "Approach Coping" was significantly higher compared to "Avoidance Coping" ( $\mathrm{p}<.001$, paired t-test). In "Approach Coping" mechanism, logical analysis was use significantly (table 4). The coping style used predominantly included problem solving (17.08) and positive reappraisal (16.97), which were used significantly more than others (table 4). In "Avoidance Coping", use of "seeking alternative rewards" was significantly more than the use of other styles (table 5). There was no major difference between 2 nd and 3rd years in the patterns of coping mechanisms.

Factors affecting stress and coping styles

Age, year of nursing education and family background did not affect stress or coping styles. However students who had not opted for nursing by choice $(18.6 \%)$ adopted coping mechanisms such as seeking guidance and support significantly less $(\mathrm{p}=0.018)$ compared to other students. A trend towards higher perceived stress especially in "academic load" and "interface worries" was also evident in them.

\section{Discussion}

Current study included 2nd and 3rd year students pursuing revised general nursing and midwifery course at a nursing college. Overall perceived stress levels were high and the major sources of stress were academic load and interface worries. A significant proportion of participants perceived stress as arising due to role conflict between clinical and academic work, fear of failure, lack of constructive feedback, inconsistent behaviour of senior faculty and restrictions imposed by them. These findings were similar to findings of previous studies by Hamill and Pagana $(3,5)$. Warbah et al has reported that high perceived stress in different domains lead to difficulties in adjustment in working environment and contribute to psychological distress. High perceived stress secondary to academic load could be attributed to a sharp transition from directive and pedagogical learning in high school, to a proactive skill based, applied learning process in nursing colleges where these students are expected to incorporate university values and skills into their existing educational expectations. Interestingly stress from clinical source and personal problems was perceived comparatively less important. A possible explanation for this could be better supervision and support while being engaged in clinical duties by staff who are usually not engaged in college academic activities. The students enrolled were

\begin{tabular}{|c|c|}
\hline Themes & Number \\
\hline $\begin{array}{l}\text { Inconsistent response and explanation } \\
\text { from faculties regarding student } \\
\text { concerns }\end{array}$ & 39 \\
\hline $\begin{array}{l}\text { Strict and over-restrictive working and } \\
\text { living environment }\end{array}$ & 36 \\
\hline Fear of failure & 22 \\
\hline Difficulty in time management & 28 \\
\hline Demeaning experiences & 19 \\
\hline Peer related stress & 08 \\
\hline $\begin{array}{l}\text { Stress related to finances and home } \\
\text { environment }\end{array}$ & 04 \\
\hline
\end{tabular}

\begin{tabular}{|c|c|c|c|c|}
\hline & $\begin{array}{l}\text { Logical } \\
\text { analysis }\end{array}$ & $\begin{array}{l}\text { Positive } \\
\text { reappraisal }\end{array}$ & $\begin{array}{l}\text { Seeking } \\
\text { guidance }\end{array}$ & $\begin{array}{l}\text { Problem } \\
\text { solving }\end{array}$ \\
\hline $\begin{array}{l}\text { Logical } \\
\text { analysis }\end{array}$ & - & \begin{tabular}{|l|}
-2.1 \\
$(p<0.001)$
\end{tabular} & $\begin{array}{l}-1.2 \\
(p=0.012)\end{array}$ & $\begin{array}{l}-2.2 \\
(p<0.001)\end{array}$ \\
\hline $\begin{array}{l}\text { Positive } \\
\text { reappraisal }\end{array}$ & $\begin{array}{l}2.1 \\
(p<0.001)\end{array}$ & - & $\begin{array}{l}0.8 \\
(p=0.295)\end{array}$ & \begin{tabular}{|l|}
-0.1 \\
$(p=1.0)$
\end{tabular} \\
\hline $\begin{array}{l}\text { Seeking } \\
\text { guidance }\end{array}$ & $\begin{array}{l}1.2 \\
(p=0.012)\end{array}$ & $\begin{array}{l}-0.8 \\
(p=0.295)\end{array}$ & - & $\begin{array}{l}-0.9 \\
(p=0.577)\end{array}$ \\
\hline $\begin{array}{l}\text { Problem } \\
\text { solving }\end{array}$ & $\begin{array}{l}-13.3 \\
(p<0.001)\end{array}$ & $\begin{array}{l}0.1 \\
(p=1.0)\end{array}$ & $\begin{array}{l}0.9 \\
(p=0.577)\end{array}$ & - \\
\hline
\end{tabular}


unmarried and dependent on their families and had no major responsibilities to their families while studying. In fact the perceived stress was less in those from larger families and those who perceived high responsibility and bonding with their families. These findings are in contrast to previous studies from the West, which have reported high perceived stress in the personal domain due to multiple role conflict. In these studies a considerable number of student nurses were married, have financial responsibilities towards their families, and hence have an additional burden in managing time because they are employed and also have to pursue nursing studies $(4,17)$.

The use of approach coping mechanisms compared to avoidance strategies in the current study group was a positive observation. However avoidance strategies were used as much as approach mechanisms in handling stress arising from academic load or interface worries. A considerable number of students $(18.6 \%)$ who had not opted for a nursing career by choice perceived higher stress levels and were not using effective coping strategies to deal with stress. Considering the high level of perceived stress in the working environment, it is important to educate these students about logical analysis, priority setting and seeking guidance as well as enhancing existing coping skills early in the student's academic career. According to Mahat all students will experience stress while in school (18). Some students may experience stress, perceive it as a challenge and become motivated to work harder and improve their learning. Other students will perceive stress more as a threat and learning may be hindered. The more capable student is stimulated by this anxiety and will strive to gain mastery over the situation. The less able students, however, will blame themselves for classroom failures and blame others for failures in interpersonal relationships. Therefore, it is important for administrators and faculty to understand the sources of stress as perceived by students and implement strategies to deal with this stress.

\section{Conclusions}

Nursing students had high levels of perceived stress, a major source of stress was academic load and interface worries. The stress due to clinical work was not perceived as more than that due to academic work or lack of appropriate interaction pattern within seniors and colleagues (interface worries). This indicates that though there has been adequate clinical skills training in the curriculum, little attention is paid to make the working environment less stressful and more conducive to a healthy interaction pattern. A positive trend was evident in use of approach over avoidance coping strategies. However time and stress management, communication skill training and use of effective coping skills for handling academic and interpersonal stress should be incorporated into the curriculum early in the nursing career.

\section{Implications}

Nursing faculty need to implement programs dealing with logical analysis, problem-solving, priority setting and effective guidance and support early in the student's academic career. It is also imperative that faculty explore strategies to improve faculty-student relationships in an effort to foster self-confidence and feelings of competence in the student. It is recommended that nursing educators re-evaluate didactic and clinical course requirements and incorporate andragogical teaching methods which recognize that most students are adults with unique needs and their own learning styles. This type of teaching will hopefully increase the program's integrity and decrease stress perceived by students. Such steps are also imperative in improving motivation and commitment of students including those who did not opt for nursing as a career by choice. Further research needs to focus on faculty perception about students and teaching styles that students identify as increasing stress.

\section{Limitations}

The main limitations were the cross sectional design and inclusion of participants from a single nursing school. However the population studied may be a representative sample since most nursing school have a similar environment and a common curriculum. Hence we feel that the findings could be generalized to other institutes in similar settings. The study did not take into account factors like student's personality, faculty and clinical staff's perception of stress in students. These factors may affect stress and coping behaviours.

\section{Declaration of interest \\ None declared}

\begin{tabular}{|c|c|c|c|c|}
\hline & $\begin{array}{l}\text { Cognitive } \\
\text { avoidance }\end{array}$ & $\begin{array}{l}\text { Acceptance } \\
\text { or } \\
\text { resignation }\end{array}$ & $\begin{array}{l}\text { Seeking } \\
\text { alternative } \\
\text { rewards }\end{array}$ & $\begin{array}{l}\text { Emotional } \\
\text { discharge }\end{array}$ \\
\hline $\begin{array}{l}\text { Cognitive } \\
\text { avoidance }\end{array}$ & - & $\begin{array}{l}1.5 \\
(p=0.017)\end{array}$ & $\begin{array}{l}-1.2 \\
(p=0.024)\end{array}$ & $\begin{array}{l}1.0 \\
(p=0.192)\end{array}$ \\
\hline $\begin{array}{l}\text { Acceptance } \\
\text { or } \\
\text { resignation }\end{array}$ & $\begin{array}{l}-1.5 \\
(p=0.017)\end{array}$ & - & $\begin{array}{l}-2.7 \\
(p<0.001)\end{array}$ & $\begin{array}{l}-0.5 \\
(p=1.0)\end{array}$ \\
\hline $\begin{array}{l}\text { Seeking } \\
\text { alternative } \\
\text { rewards }\end{array}$ & $\begin{array}{l}1.2 \\
(p=0.024)\end{array}$ & $\begin{array}{l}2.7 \\
(p<0.001)\end{array}$ & - & $\begin{array}{l}2.3 \\
(p<0.001)\end{array}$ \\
\hline $\begin{array}{l}\text { Emotional } \\
\text { discharge }\end{array}$ & $\begin{array}{l}-1.0 \\
(p=0.192) \\
(p<0.001)\end{array}$ & $\begin{array}{l}0.5 \\
(p=1.0)\end{array}$ & $\begin{array}{l}-2.3 \\
(p<0.001)\end{array}$ & - \\
\hline
\end{tabular}

Aniket Shukla, Assistant Professor,

Department of Psychiatry, JNMC and AVBR

Hospital, DMIMS(DU), Sawangi (meghe), Wardha, India

Gurvinder Kalra, Assistant Professor

Department of Psychiatry, MGM Medical College

and Hospital, New Mumbai, India

Abhijit Pakhare, Assistant Professor

Department of Community \& Family Medicine, All India Institute of Medical Sciences (AIIMS), Bhopal, India

Corresponding author

Aniket Shukla

E mail: aniketdshukla@gmail.com 


\section{References}

1. Schluter PJ, Turner C, Huntington AD, Bain CJ, McClure RJ. Work/life balance and health: the Nurses and Midwives e-cohort Study. Int Nurs Rev 2011;58(1):28-36.

2. Nair S, Percot M. Transcending boundaries: Indian nurses in internal and international migration. Occasional Paper, Centre for Women's Development Studies, New Delhi. 2005; retieved from, http://www.cwds.ac.in/OCPaper/ Transcending-sreelekha-ocpaper.pdf.

3. Hamill C. The phenomena of stress as perceived by Project 2000 student nurses: a case study. J Adv Nurs 1995;21:528-36.

4. Beck DL, Srivastava R. Perceived level and sources of stress in baccalaureate nursing students. J Nurs Educ 1991;30(3):127-33.

5. Pagana KD. Stresses and threats reported by baccalaureate students in relation to an initial clinical experience. J Nurs Educ 1988;27(9):41824.

6. Lengacher CA. Role strain, role stress and anxiety in nursing faculty and students: theory and research analysis. In KR Stevens (Ed.), Review of Research in Nursing Education, volume VII, (pp.40-60). New York, NY: National League for Nursing; 1996.

7. Warbah L, Sathiyaseelan M, Vijayakumar C, Vasantharaj B, Russell S, Jacob KS. Psychological distress, personality, and adjustment among nursing students. Nurse Educ Today 2007;27(6):597-601.

8. Angelone AM, Mattei A, Sbarbati M, DiOrio F. Prevalence and correlates for self-reported sleep problems among nursing students. J Prev Med Hyg 2011;52(4):201-8.
9. Piko B, Piczil M. Study of stress, coping and psychosomatic health among baccalaureate nursesto-be. Orv Hetil 2012;153(31):1225-33.

10. Chan CK, So WK, Fong DY. Hong Kong baccalaureate nursing students' stress and their coping strategies in clinical practice. J Prof Nurs 2009;25(5):307-13.

11. Jones MC. Johnston DW. Derivation of a brief student nurse stress index. Work Stress 1999;13(2):162-81.

12. Moos RH. The coping responses inventory manual. Palo Alto CA: Social Ecology Laboratory, Stanford University \& Department of Veterans Affairs Medical Centers 1988.

13. Moos RH. Coping Responses Inventory: Adult form (Professional Manual). Odessa, FL: Psychological Assessment Resources, Inc. 1993.

14. Wong PTP, Reker GT, Peacock EJ. A resourcecongruence model of coping and the development of the coping schemas inventory. In PTP Wong \& LCJ Wong (Eds.), Handbook of multicultural perspectives on stress and coping, illustrated edition. (pp.230), New York, NY: Springer;2006.

15. Davidson S, Dew MA, Penkower L, Becker JT, Kingsley L, Sullivan PF. Substance use and sexual behavior among homosexual men at risk for HIV infection: Psychosocial moderators. Psychol Health 1992;7:259-72.

16. Finney J, Moos R. Entering treatment for alcohol abuse: A stress and coping model. Addiction 1995;90:1223-40.

17. Howard D. Student nurses' experiences of Project 2000. Nurs Stand 2001;15(48):33-8.

18. Mahat G. Stress and coping: junior baccalaureate nursing students in clinical settings. Nurs Forum 1998;33(1):11-9. 